\title{
Characteristics of hydrogen and bioflocculant production by a transposon- mutagenized strain of Pantoea agglomerans BH18
}

Hongyan Liu * Hongyu Wang Haihua Qin

Abstract: Based on the transposon-mutagenized library of Pantoea agglomerans BH18, the mutant strain 2-103 was obtained using mutant screens for high simultaneous production of hydrogen and bioflocculant. The mutant strain 2-103 was able to grow in medium with $50 \mu \mathrm{g} / \mathrm{mL}$ of kanamycin and could be amplified using Tn7-based transposon PCR amplification in cells from several passages, indicating that the mutant strain 2-103 transposon insertion was stable. The mutant strain 2-103 cell culture from batch experiments with varying initial $\mathrm{pH}$ values, glucose concentrations and $\mathrm{NaCl}$ concentrations was determined. The result indicated that the optimum initial $\mathrm{pH}$ for hydrogen production and bioflocculant activity was 7.0 and 8.0, respectively. The optimal glucose concentration for hydrogen and bioflocculant production was $20 \mathrm{~g} / \mathrm{L}$. In addition, the mutant strain 2-103 could produce hydrogen and bioflocculant under marine and fresh culture conditions. The mutant strain 2-103 had the highest production of hydrogen and bioflocculant with $(1.55 \pm 0.07) \mathrm{mol} \mathrm{H}_{2} /$ mol glucose and $(83.7 \pm 5.89) \%$ under marine culture conditions, which increased to $(1.78 \pm 0.08) \mathrm{mol} \mathrm{H} / \mathrm{mol}$ glucose and $(93.5 \pm 6.24) \%$ under fresh culture conditions. This study found that the mutant strain 2-103 has the ability to produce hydrogen and 
bioflocculant within a range of initial $\mathrm{pH}$ values, glucose and $\mathrm{NaCl}$ concentrations, which is beneficial for the improvement of cost-effective bio-treatment processes.

Keywords: Transposon-mutagenized library; Mutant screen; Hydrogen production; Bioflocculant activity

\section{Introduction}

Hydrogen is recognized as one of the most promising energy carriers [1]. Microbial hydrogen production by photosynthetic bacteria or fermentative bacteria has been demonstrated to be an effective process for hydrogen generation. Hydrogen production by fermentative bacteria is technically simpler than production by photosynthetic bacteria. In addition, fermentative hydrogen production can utilize a variety of renewable energy sources such as organic waste and is recognized as a promising approach [2]. Although fermentative hydrogen production has attracted great interest in research recently, this method has not been implemented in largescale processing due to some major issues that remain unresolved. One of these issues is the production of potentially harmful by-products resulting from the fermentative hydrogen-producing process, such as waste fermenting liquor [3]. Waste fermenting liquor contains high levels of organic substances and requires further treatment before disposal [4]. This issue needs to be resolved before hydrogen production is industrialized using this method.

Bioflocculants received practical attention in wastewater treatment, as they are biodegradable and regarded to be environmentally safe [5-6]. However, the high production cost is still the major impediment to the industrial application of bioflocculants. To reduce the cost of bioflocculant production, several low-cost substrates, such as rice straw, starch wastewater and fermenting waste liquor, were 
researched and utilized by bioflocculant-producing microbial strains [7-9]. The procedure of using the fermenting liquor to produce bioflocculants has been recognized as an effective solution for cost-effective bioflocculant production and disposal of fermenting liquor [10].

Studies investigating the utilization of fermenting liquor from hydrogen production found that some strains (Enterobacter sp. BY-29 [11], Ethanoligenens harbinense [12], Bacillus sp. XF-56 [13]) have the ability to produce hydrogen and bioflocculant simultaneously. Applying techniques that utilize hydrogen-producing bacteria that simultaneously produce bioflocculant helps reduce the cost of wastewater treatment.

To date, strains able to produce hydrogen and bioflocculant simultaneously were mainly obtained using wild type screening. In order to expand microbial resources and clarify the mechanism of simultaneous hydrogen and bioflocculant production by hydrogen-producing bacteria, it is necessary to employ molecular biology techniques [14-15]. Classically, transposon mutagenesis has been demonstrated to be an excellent tool for mutating microorganisms in bacterial genetic research [16]. In a previous study, we constructed a transposon-mutagenized library of Pantoea agglomerans BH18. This library consisted of a population of insertion mutants with the transposable element at variable positions [17]. To the best of our knowledge, there have been no reports that assess simultaneous hydrogen production and the bioflocculant activity of bacterial strains using molecular biology techniques.

In this study, we screened the transposon-mutagenized strain 2-103, which has the potential for simultaneous hydrogen and bioflocculant production. Batch experiments for hydrogen and bioflocculant production by the mutant strain 2-103 were performed with varying initial $\mathrm{pH}$ values, glucose and $\mathrm{NaCl}$ concentrations. On the basis of the 
transposon-mutagenized Pantoea agglomerans BH18 library, this study provides an effective approach to investigate the characteristics of hydrogen and bioflocculant production by hydrogen-producing bacteria. These results provide valuable insights into the development of cost-effective approaches for industrializing hydrogen production.

\section{Materials and Methods}

\subsection{Strain and culture growth}

Pantoea agglomerans BH18 (NO. EU590682) was grown in LM-H medium as described previously [17]. The medium (g/L) was composed of glucose 10.0 , tryptone 4.0, yeast extract 1.0, beef extract 2.0, $\mathrm{NaCl} 30.0, \mathrm{~K}_{2} \mathrm{HPO}_{4} 1.5, \mathrm{FeSO}_{4} 0.1, \mathrm{MgCl}_{2} 0.1$ and L-cysteine 0.5. The transposon-mutagenized strains of Pantoea agglomerans BH18 were inoculated in the same medium supplemented with $50 \mu \mathrm{g} / \mathrm{mL}$ kanamycin sulfate. Pantoea agglomerans $\mathrm{BH}-18$ and the mutant strains were incubated at $37^{\circ} \mathrm{C}$ with a shaking speed of $120 \mathrm{rpm}$ under anaerobic conditions.

\subsection{Screening for mutant strains}

In the primary screening, the mutant strains were cultured in the medium, as follows (g/L): glucose 10.0, yeast extract 0.5, urea 0.5, $\mathrm{NaCl} 30.0, \mathrm{KH}_{2} \mathrm{PO}_{4} 2.0, \mathrm{~K}_{2} \mathrm{HPO}_{4} 5.0$ and $\mathrm{MgSO}_{4}$ 0.2. After 2 days of growth at $37^{\circ} \mathrm{C}$, these transformed cell cultures were spread onto the same medium agar plates with $50 \mu \mathrm{g} / \mathrm{mL}$ kanamycin sulfate. After cultivating for 2 days, single colonies with mucoid and ropy morphology were selected and transferred to the liquid medium for culture. In the secondary screening, hydrogen production and bioflocculant activity by the mutant strains were determined. Wild type strain Pantoea agglomerans BH18 was used as the control. Finally, the 
mutant strain with the highest hydrogen and bioflocculant production was isolated.

\section{The stability of the transposon insertion generated by the mutant strain was tested}

using the following method. Briefly, at the end of fermentative hydrogen production, $1 \mathrm{~mL}$ of cell suspension was transferred into $100 \mathrm{~mL}$ of medium with $50 \mu \mathrm{g} / \mathrm{mL}$ kanamycin sulfate. After 2 days of anaerobic incubation, $1 \mathrm{~mL}$ of culture broth was inoculated for the next cultivation using the same medium under anaerobic conditions. After four subcultures, genomic DNA of the aliquot cells was extracted as a template for polymerase chain reaction to confirm the transposon insertion. The transposonspecific PCR (primer TnL: TTAAGGATTATTTAGGGAAG; TnR: ACAATAAAGTCTTAAAC) was conducted as follows: initial denaturation of DNA for $4 \mathrm{~min}$ at $94^{\circ} \mathrm{C} ; 30$ cycles at $94^{\circ} \mathrm{C}$ for $30 \mathrm{~s}$, at $49^{\circ} \mathrm{C}$ for $30 \mathrm{~s}$, at $72^{\circ} \mathrm{C} 30 \mathrm{~s}$ and extension of incomplete products at $72^{\circ} \mathrm{C}$ for $10 \mathrm{~min}$.

\subsection{Optimization of batch conditions}

The effects of initial $\mathrm{pH}$, glucose concentration and $\mathrm{NaCl}$ concentration on cell growth, hydrogen production and bioflocculant activity by the mutant strain were determined. To determine the optimum initial $\mathrm{pH}$ value for production of hydrogen and bioflocculant, the following range of $\mathrm{pH}$ values was selected: 5.0, 6.0, 7.0, 8.0, 9.0 and 10.0. A range of glucose concentrations $(5,10,20,30,40$ and $50 \mathrm{~g} / \mathrm{L})$ and $\mathrm{NaCl}$ concentrations $(0,4,30,40,50$ and $60 \mathrm{~g} / \mathrm{L})$ were used in the batch operations. All tests were performed in triplicate.

\subsection{Analytical methods}

The cell growth of the mutant strain was determined by optical absorbance at $600 \mathrm{~nm}$ 
using a spectrophotometer (UV-1800, Shimadzu). Hydrogen production was determined using a gas chromatograph (Model 6820, Agilent). In detail, biogas production was collected using the drainage method. The chromatograph was equipped with a thermal conductivity detector and nitrogen at the speed of $30 \mathrm{~mL} / \mathrm{min}$ was used as the carrier gas. The oven, injector and detector were kept at 40, 200 and $200^{\circ} \mathrm{C}$, respectively. The bioflocculant activity was measured by kaolin suspension according to methods described previously [18]. The kaolin suspension was prepared by adding $0.5 \mathrm{~g}$ kaolin clay to $100 \mathrm{~mL}$ deionized water and mixed with $0.5 \mathrm{~mL}$ of $10 \% \mathrm{CaCl}_{2}$ solution. Next, $0.5 \mathrm{~mL}$ of fermenting liquor was added to the $100 \mathrm{~mL}$ of kaolin suspension and the $\mathrm{pH}$ value was adjusted to 7.0. The mixture was stirred at $120 \mathrm{rpm}$ for $30 \mathrm{~s}$, and allowed to stand for $10 \mathrm{~min}$. The optical density of the upper solution was measured using a spectrophotometer (UV-1800, Shimadzu) at $550 \mathrm{~nm}$. The mixed solution without bioflocculant was used as the blank control. The bioflocculant activity was calculated as follows: bioflocculant activity $=\left(\mathrm{OD}_{\mathrm{A}}-\mathrm{OD}_{\mathrm{B}}\right) /$ $\mathrm{OD}_{\mathrm{A}} * 100$, where $\mathrm{OD}_{\mathrm{A}}$ and $\mathrm{OD}_{\mathrm{B}}$ represent the optical densities of the control and the sample at $550 \mathrm{~nm}$, respectively.

\section{Results and Discussion}

\subsection{Screening for the mutant strain 2-103}

Based on the transposon-insertion library of Pantoea agglomerans BH18, we isolated nine mutant strains whose hydrogen production and bioflocculant activity exceeded that of the wild type strain by $20 \%$. Of these transposon-mutagenized strains, the mutant strain with the highest hydrogen and bioflocculant production was screened and named as strain 2-103. Hydrogen production of the mutant strain 2-103 (1.55 \pm 
$0.07 \mathrm{~mol} \mathrm{H}_{2} / \mathrm{mol}$ glucose under marine conditions) exceeded that of the wild type strain by $40 \%$. The mutant strain $2-103$ produced bioflocculant as a byproduct during fermentative hydrogen production. The bioflocculant activity of the mutant strain 2-103 was $(83.7 \pm 5.89) \%$, which was approximately 2.5 -fold greater than that of the wild type strain. To the best of our knowledge, this report describes the first time a transposon-mutagenized strain with simultaneous hydrogen and bioflocculant production was obtained using molecular biology techniques.

The mutant strain 2-103 was replated in the medium with kanamycin to test the stability of the transposition event. Figure 1 shows that the Tn7-based transposon with a 1699 bp transposon fragment was amplified by mutant strain 2-103 in the cells from several passages. These results indicate that the kanamycin resistance was maintained and that the target transposon fragment of the mutant strain 2-103 was stable and effective.

\subsection{Bacterial growth}

To determine the cell growth of the mutant strain 2-103 during the fermentation, the optical absorbance at $600 \mathrm{~nm}$ was monitored at various time intervals. As shown in Figure 2, the mutant strain 2-103 grew logarithmically after $12 \mathrm{~h}$ and arrived at a stationary phase at $24 \mathrm{~h}$. At this stationary phase, cell growth of the mutant strain 2-103 reached its maximum. For the wild strain Pantoea agglomerans BH18, the time that cells reached the exponential phase and stationary phase was 8 and $16 \mathrm{~h}$, respectively. The mutant strain 2-103 showed slower growth compared with the wild type. In general, cell growth of genetically engineered mutants is usually decreased when compared to the wild type strain [19]. 
The mutant strain 2-103 began to produce hydrogen in the late exponential phase, with maximum hydrogen production occurring between 24 and $48 \mathrm{~h}$. As shown in Figure 2, hydrogen production and cell growth was not synchronous. This phenomenon is similar to what had been observed in a previous report [20]. The bioflocculant activity of the mutant strain 2-103 was also determined at different time intervals. Figure 2 shows that bioflocculant activity increased with increments of cell growth and had a remarkable improvement during the stationary phase (24-36 h). This result is consistent with prior studies that revealed that bioflocculant production was almost in parallel with cell growth of Bacillus mojavensis 32A and Chryseobacterium daeguense W6 [15, 21].

\subsection{Effects on the production of hydrogen and bioflocculant}

\subsubsection{Initial $\mathrm{pH}$}

The effects of initial medium $\mathrm{pH}$ on cell growth and production of hydrogen and bioflocculant were investigated. As shown in Table 1, the mutant strain 2-103 could grow at a wide range of initial $\mathrm{pH}$ values (5.0-10.0). The optimum initial $\mathrm{pH}$ for cell growth and hydrogen production of the mutant strain 2-103 was at 8.0 and 7.0, respectively, which indicated again that hydrogen generation was not in parallel with cell growth [22]. The maximum hydrogen production yield $(1.55 \pm 0.07) \mathrm{mol} \mathrm{H} / \mathrm{mol}$ glucose by the mutant strain 2-103 was obtained at the optimum initial $\mathrm{pH}$ of 7.0. The initial $\mathrm{pH}$ of the medium is known to be an important factor influencing hydrogen production. Disagreements exist regarding the optimum $\mathrm{pH}$ for hydrogen-producing strains isolated from different environments. The reported optimum $\mathrm{pH}$ values for hydrogen production range from 6.0 to 8.0 [23-25].

The mutant strain 2-103 was isolated and grown under marine conditions. The 
optimum initial $\mathrm{pH}$ for cell growth and bioflocculant production by the mutant strain 2-103 was 8.0, which is consistent with the $\mathrm{pH}$ of seawater. The maximum bioflocculant activity of the mutant strain $2-103$ was $(87.5 \pm 6.38) \%$ at an initial $\mathrm{pH}$ of 8.0. The bioflocculant activity and cell growth by the mutant strain 2-103 simultaneously reached their maximum at an initial $\mathrm{pH}$ of 8.0 . This result is similar to a previous report that demonstrated a close relationship between cell growth and bioflocculant production in Paenibacillus polymyxa AM49 [26].

\subsubsection{Glucose concentration}

Glucose was used as a carbon source during anaerobic cultivation of the mutant strain 2-103. The effect of initial glucose concentration on the production of hydrogen and bioflocculant was examined. Figure 3 shows that the initial glucose concentration had a noticeable effect on cell growth and hydrogen production. With increasing glucose concentrations (from 5 to $50 \mathrm{~g} / \mathrm{L}$ ), cell growth of the mutant strain 2-103 first increased and subsequently decreased. The optimum glucose concentration for cell growth of the mutant strain 2-103 was $20 \mathrm{~g} / \mathrm{L}$. Maximum hydrogen production $(1.68 \pm$ $0.08 \mathrm{~mol} \mathrm{H}_{2} / \mathrm{mol}$ glucose) of the mutant strain 2-103 also occurred at a glucose concentration of $20 \mathrm{~g} / \mathrm{L}$. Many strains were previously reported to effectively use glucose as a carbon source for hydrogen production with different optimum glucose concentrations ranging from 4 to $40 \mathrm{~g} / \mathrm{L}$ [27-28].

Glucose concentration is an important parameter for bioflocculant production because low initial concentrations could result in low biomass accumulation, long lag times and a low rate of fermentation [29]. Figure 3 also shows the effect of glucose concentration on bioflocculant activity. Different glucose concentrations led to 
changes in bioflocculant activity of the mutant strain 2-103. Bioflocculant activity reached its maximum $(91.5 \pm 5.82 \%)$ when the initial glucose concentration was 20 $\mathrm{g} / \mathrm{L}$. In accordance with our results, some reports also utilized glucose as the optimum carbon source for bioflocculant production with glucose concentrations fixed at 10-20 $\mathrm{g} / \mathrm{L}[30-31]$

\subsection{3. $\mathrm{NaCl}$ concentration}

Salt is essential for cells and is composed primarily of $\mathrm{NaCl}$. $\mathrm{NaCl}$ concentration is one of the most important parameters influencing hydrogen production and bioflocculant activity [32-33]. The properties of hydrogen and bioflocculant by the mutant strain 2-103 under fresh and marine culture conditions were investigated. As seen in Figure 4, differences in hydrogen and bioflocculant production by the mutant strain 2-103 were observed at various $\mathrm{NaCl}$ concentrations $(0,4,30,40,50$ and $60 \mathrm{~g} /$ L). Hydrogen production and bioflocculant activity of the mutant strain 2-103 decreased as $\mathrm{NaCl}$ concentrations increased. Hydrogen production and bioflocculant activity was obviously weak at a $\mathrm{NaCl}$ concentration of $60 \mathrm{~g} / \mathrm{L}$. Under marine conditions $(\mathrm{NaCl}$ concentration of $30 \mathrm{~g} / \mathrm{L})$, the maximum hydrogen production and bioflocculant activity by the mutant strain $2-103$ was $(1.55 \pm 0.07) \mathrm{mol} \mathrm{H}_{2} / \mathrm{mol}$ glucose and $(83.7 \pm 5.89) \%$ respectively, whereas under the fresh culture condition $(\mathrm{NaCl}$ concentration of $4 \mathrm{~g} / \mathrm{L})$ it increased to $(1.78 \pm 0.08) \mathrm{mol} \mathrm{H}_{2} / \mathrm{mol}$ glucose and $(93.5 \pm 6.24) \%$

The mutant strain 2-103 was able to grow and produce hydrogen and bioflocculant at all $\mathrm{NaCl}$ concentration ranges tested, which indicated that the mutant strain was a salt-tolerant bacterium as it was able to function under either fresh or marine culture 
conditions. Pantoea agglomerans BH18 was isolated from mangrove sludge. Among various marine environments, mangrove is located at the transition between marine and terrestrial environments with drastic variations in $\mathrm{NaCl}$ concentrations. The mutant strain 2-103 basically maintained its salt-tolerance from the wild type strain. These results suggest that the strain 2-103 may have the potential to be used for the production and clarification of biohydrogen under a wide range of water types from fresh to marine conditions.

\section{Conclusions}

The mutant strain 2-103, which could produce hydrogen and bioflocculant simultaneously, was screened based on the transposon-mutagenized library of Pantoea agglomerans BH18. The transposition event of the mutant strain 2-103 was found to be highly stable during the several passages. In batch cultures of the mutant strain 2-103, the optimum condition for hydrogen production and bioflocculant activity was in medium containing an initial $\mathrm{pH}$ of $7.0(8.0)$, glucose concentration of

$20 \mathrm{~g} / \mathrm{L}$ (as a carbon source) and $\mathrm{NaCl}$ concentration of $4 \mathrm{~g} / \mathrm{L}$. The highest production of hydrogen and bioflocculant by the mutant strain 2-103 was $(1.78 \pm 0.08) \mathrm{mol} \mathrm{H}_{2} /$ mol glucose and $(93.5 \pm 6.24) \%$, respectively during the $72 \mathrm{~h}$ cultivation period under fresh culture conditions. This study revealed that the mutant strain 2-103 could simultaneously produce hydrogen and bioflocculant, which will largely reduce the productive costs of hydrogen and bioflocculants and has the characteristics desired for application in cost-effective wastewater treatments.

\section{Acknowledgments}


The authors acknowledge the financial support by the Natural Science Foundation of Tianjin, China (16JCYBJC20900, 12JCQNJC04200) and the Foundation of Tianjin Key Laboratory of Marine Resources and Chemistry (Tianjin University of Science \& Technology) (No. 201302).

\section{References}

1. Cheng X, Liu C. Hydrogen production via thermophilic fermentation of cornstalk by Clostridium thermocellum. Energy Fuels 2011; 25: 1714-20.

2. Jiang L, Zhu L Y, Xu X, Lin M, Li Y P, Li X T, et al. Bioproduction of hydrogen by simultaneous saccharification and fermentation of cassava starch with 2deoxyglucose-resistant mutant strains of Clostridium tyrobutyricum. Int $\mathrm{J}$ Hydrogen Energy 2013; 38: 6349-56.

3. Xing D F, Ren N Q, Wang A J, Li Q B, Feng Y J, Ma F. Continuous hydrogen production of auto-aggregative Ethanoligenens harbinense YUAN-3 under nonsterile condition. Int J Hydrogen Energy 2008; 33: 1489-95.

4. You Y, Ren N Q, Wang A J, Ma F, Gao L, Peng Y Z, et al. Use of waste fermenting liquor to produce bioflocculants with isolated strains. Int J Hydrogen Energy 2008; 33: 3295-301.

5. Wang L, Lee D J, Ma F, Wang A J, Ren N Q. Bioflocculants from isolated strain or mixed culture: Role of phosphate salts and $\mathrm{Ca}^{2+}$ ions. J Taiwan Inst Chem $\mathrm{E}$ $2014 ; 45: 527-32$

6. Yim J H, Kim J S, Anh S H, Lee H K. Characterization of a novel bioflocculant, p-KG03, from a marine dinoflagellate, Gyrodinium impudicum KG03. Bioresour Technol 2007; 98: 361-7. 
7. Zhao G, Ma F, Wei L, Chua H. Using rice straw fermentation liquor to produce bioflocculants during an anaerobic dry fermentation process. Bioresour Technol 2012; 113: 83-8.

8. Liu Z Y, Hu Z Q, Wang T, Chen Y Y, Zhang J B, Yu J R, et al. Production of novel microbial flocculants by Klebsiella sp. TG-1 using waste residue from the food industry and its use in defecating the trona suspension. Bioresour Technol 2013; 139: 265-71.

9. Sam S, Kucukasik F, Yenigun O, Nicolaus B, Oner E T, Yukselen M A. Flocculating performances of exopolysaccharides produced by a halophilic bacterial strain cultivated on agro-industrial waste. Bioresour Technol 2011; 102 (2): $1788-94$.

10. Jia B J, Yu J M. The research status and development trend of microbial flocculant. Physics Procedia 2012; 24: 425-8.

11. Yokoi H, Aratake T, Hirose J, Hayashi S, Takasaki Y. Simultaneous production of hydrogen and bioflocculant by Enterobacter sp. BY-29. World J Microb Biotechnol 2001; 17: 609-13.

12. Ren N Q, Xie T H, Xing D F. Composition of extracellular polymeric substances influences the autoaggregation capability of hydrogen-producing bacterium Ethanoligenens harbinense. Bioresour Technol 2009; 100: 5109-13.

13. Liu H Y, Chen G C, Wang G C. Characteristics for production of hydrogen and bioflocculant by Bacillus sp. XF-56 from marine intertidal sludge. Int J Hydrogen Energy 2015; 40: 1414-19.

14. Trchounian K, Abrahamyan V, Poladyan A, Trchounian A. Escherichia coli growth and hydrogen production in batch culture upon formate alone and with 
glycerol co-fermentation at different pHs. Int J Hydrogen Energy 2015; 40: 9935-41.

15. Elkady M F, Soha F, Sahar Z, Abu-elreesh G, Abdelhaleem D. Bacillus mojavensis strain 32A, a bioflocculant-producing bacterium isolated froman Egyptian salt production pond. Bioresour Technol 2011; 102: 8143-51.

16. Carr J F, Gregory S T, Dahlberg A E. Transposon mutagenesis of the extremely thermophilic bacterium Thermus thermophilus HB27. Extremophiles 2015; 19(1): $221-8$

17. Liu H Y, Wang G C, Zhu D L, Pan G H. Improvement of hydrogen production by transposon-mutagenized strain of Pantoea agglomerans BH18. Int J Hydrogen Energy 2012; 37: 8282-7.

18. Sathiyanarayanan G, Kiran G S, Selvin J. Synthesis of silver nanoparticles by polysaccharide bioflocculant produced from marine Bacillus subtilis MSBN17. Colloids Surf B 2013; 102: 13-20.

19. Zhu Y, Liu X, Yang S T. Construction and characterization of pta gene-deleted mutant of Clostridium tyrobutyricum for enhanced butyric acid fermentation. Biotechnol Bioeng 2005; 90: 154-66.

20. Khamtib S, Reungsang A. Biohydrogen production from xylose by Thermoanaerobacterium thermosaccharolyticum KKU19 isolated from hot spring sediment. Int J Hydrogen Energy 2012; 37: 12219-28.

21. Liu W, Wang K, Li B, Yuan H, Yang J. Production and characterization of an intracellular bioflocculant by Chryseobacterium daeguense W6 cultured in low nutrition medium. Bioresour Technol 2010; 101: 1044-8.

22. Kim D G, La H J, Ahn C Y, Park Y H, Oh H M. Harvest of Scenedesmus sp. with 
bioflocculant and reuse of culture medium for subsequent high-density cultures. Bioresour Technol 2011; 102: 3163-8.

23. Fang $\mathrm{H} \mathrm{H} \mathrm{P,} \mathrm{Li} \mathrm{C} \mathrm{L,} \mathrm{Zhang} \mathrm{T.} \mathrm{Acidophilic} \mathrm{biohydrogen} \mathrm{production} \mathrm{from} \mathrm{rice}$ slurry. Int J Hydrogen Energy 2006; 31: 683-92.

24. Ramos C, Buitrón G, Moreno-Andrade I, Chamy R. Effect of the initial total solids concentration and initial $\mathrm{pH}$ on the bio-hydrogen production from cafeteria food waste. Int J Hydrogen Energy 2012; 37: 13288-95

25. Lin $\mathrm{Y} \mathrm{H}$, Juan $\mathrm{M} \mathrm{L}$, Hsien $\mathrm{H} \mathrm{J}$. Effects of temperature and initial $\mathrm{pH}$ on biohydrogen production from food-processing wastewater using anaerobic mixed cultures. Biodegradation 2011; 22(3): 551-63.

26. Kim D G, La H J, Ahn C Y, Park Y H, Oh H M. Harvest of Scenedesmus sp. with bioflocculant and reuse of culture medium for subsequent high-density cultures. Bioresour Technol 2011; 102(3): 3163-8.

27. Cai G Q, Jin B, Saint C, Monis P. Metabolic flux analysis of hydrogen production network by Clostridium butyricum W5: Effect of $\mathrm{pH}$ and glucose concentrations. Int J Hydrogen Energy 2010; 35: 6681-90.

28. Hye J J, Lee D S, Kim J, Park J M. Effect of initial glucose concentrations on carbon and energy balances in hydrogen-producing Clostridium tyrobutyricum JM1. J Microbiol Biotechnol 2009; 19: 291-8.

29. Argun H, Kargi F, Kapdan I K. Microbial culture selection for bio-hydrogen from waste ground wheat by dark fermentation. Int J Hydrogen Energy 2009; 34: 2195-200.

30. Giri S S, Harshiny M, Sen S S, Sukumaran v, Park S C. Production and characterization of a thermostable bioflocculant from Bacillus subtilis F9, 
isolated from wastewater sludge. Ecotoxicol Environ Saf 2015; 121: 45-50.

31. Yin Y J, Tian Z M, Tang W, Li L, Song L Y, McElmurry S P. Production and characterization of high efficiency bioflocculant isolated from Klebsiella sp. ZZ-3. Bioresour Technol 2014; 171: 336-42.

32. Pierra M, Trably E, Godon J J, Bernet N. Fermentative hydrogen production under moderate halophilic conditions. Int J Hydrogen Energy 2014; 39: 7508-17.

33. Liu C, Wang K, Jiang J H, Liu W J, Jing-Yuan Wang J Y. A novel bioflocculant produced by a salt-tolerant, alkaliphilic and biofilm-forming strain Bacillus agaradhaerens C9 and its application in harvesting Chlorella minutissima UTEX2341. Biochem Eng J 2015; 93: 166-72.

Legend

Fig. 1 The identification of transposon insertion by PCR amplification of the mutant strain 2-103

M: Marker, W: Wild type strain, 1-5: PCR products of transposon Tn7 insertion in the five consecutive passages by the mutant strain 2-103

Fig. 2 Variation of cell growth, hydrogen production and bioflocculant activity by the mutant strain 2-103 during the fermentation $(\mathrm{n}=3$, Error bars $=$ s.e.m. $)$ 
Fig. 3 Effect of glucose concentration on cell growth, hydrogen production and bioflocculant activity by the mutant strain 2-103 $(n=3$, Error bars $=$ s.e.m. $)$

Fig. 4 Effect of $\mathrm{NaCl}$ concentration on cell growth, hydrogen production and bioflocculant activity by the mutant strain 2-103 $(n=3$, Error bars = s.e.m. $)$

Tab.1 Cell growth, hydrogen production and bioflocculant activity by the mutant strain 2-103 in different initial $\mathrm{pH}$ using $10 \mathrm{~g} / \mathrm{L}$ glucose as carbon source 


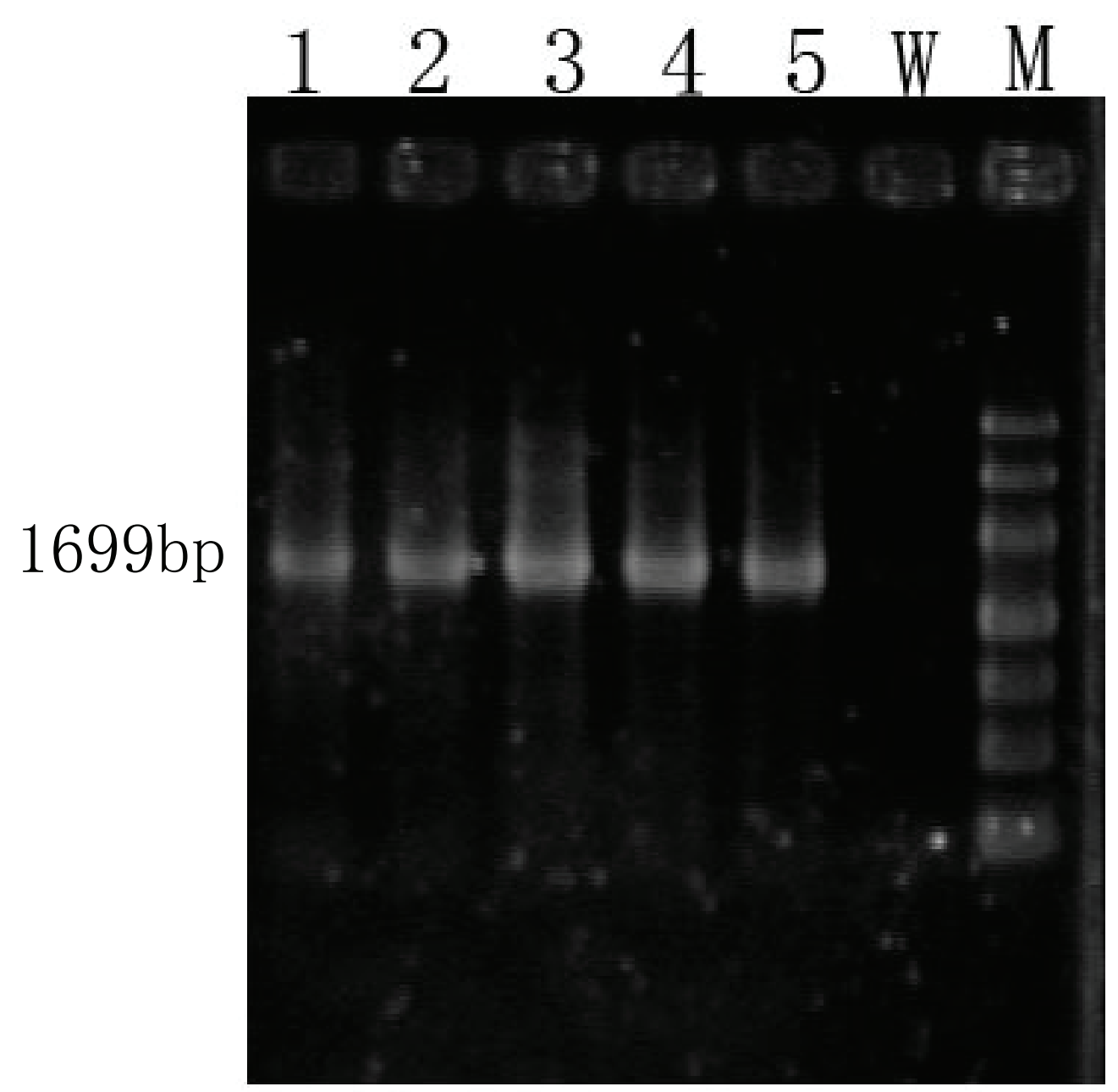




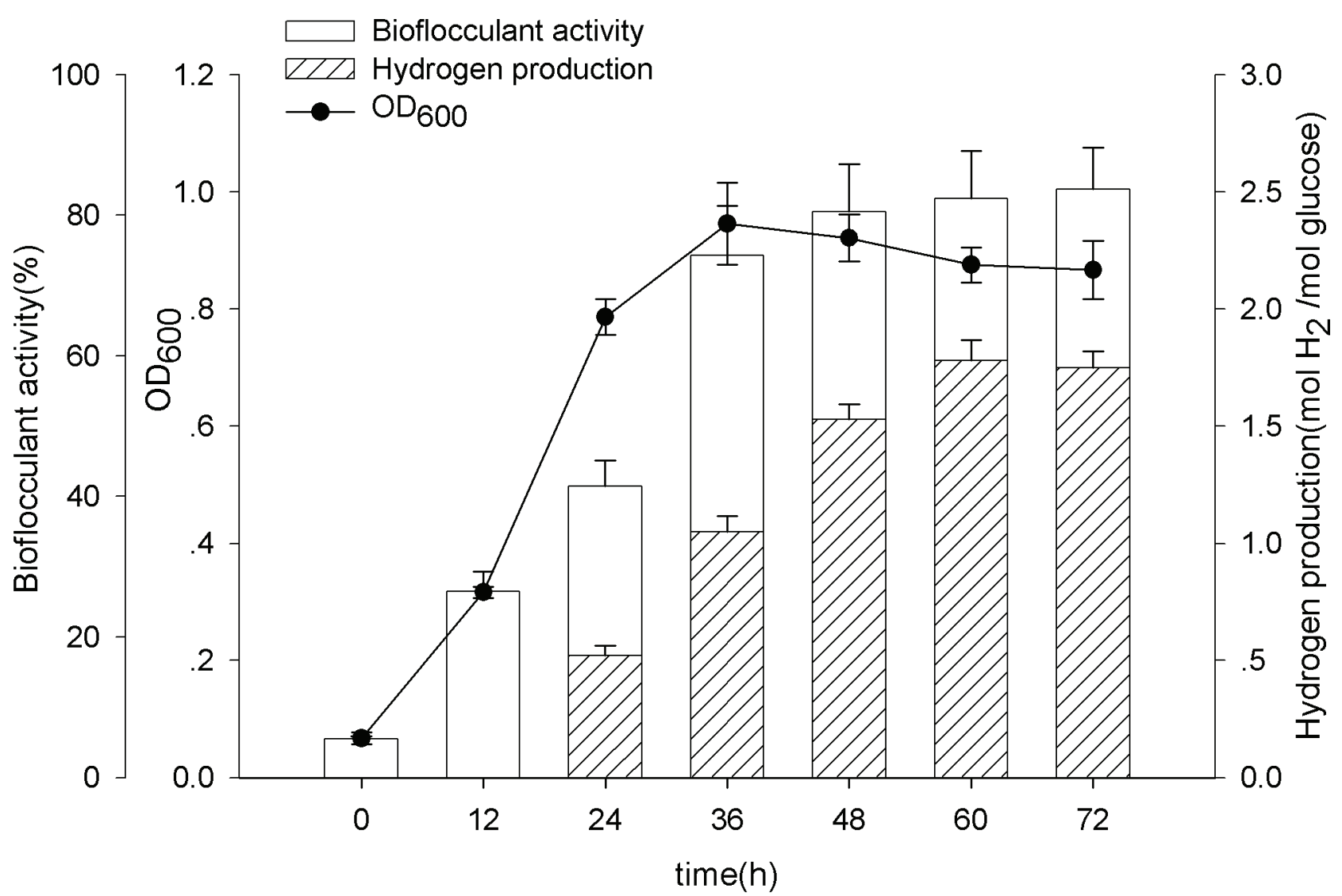




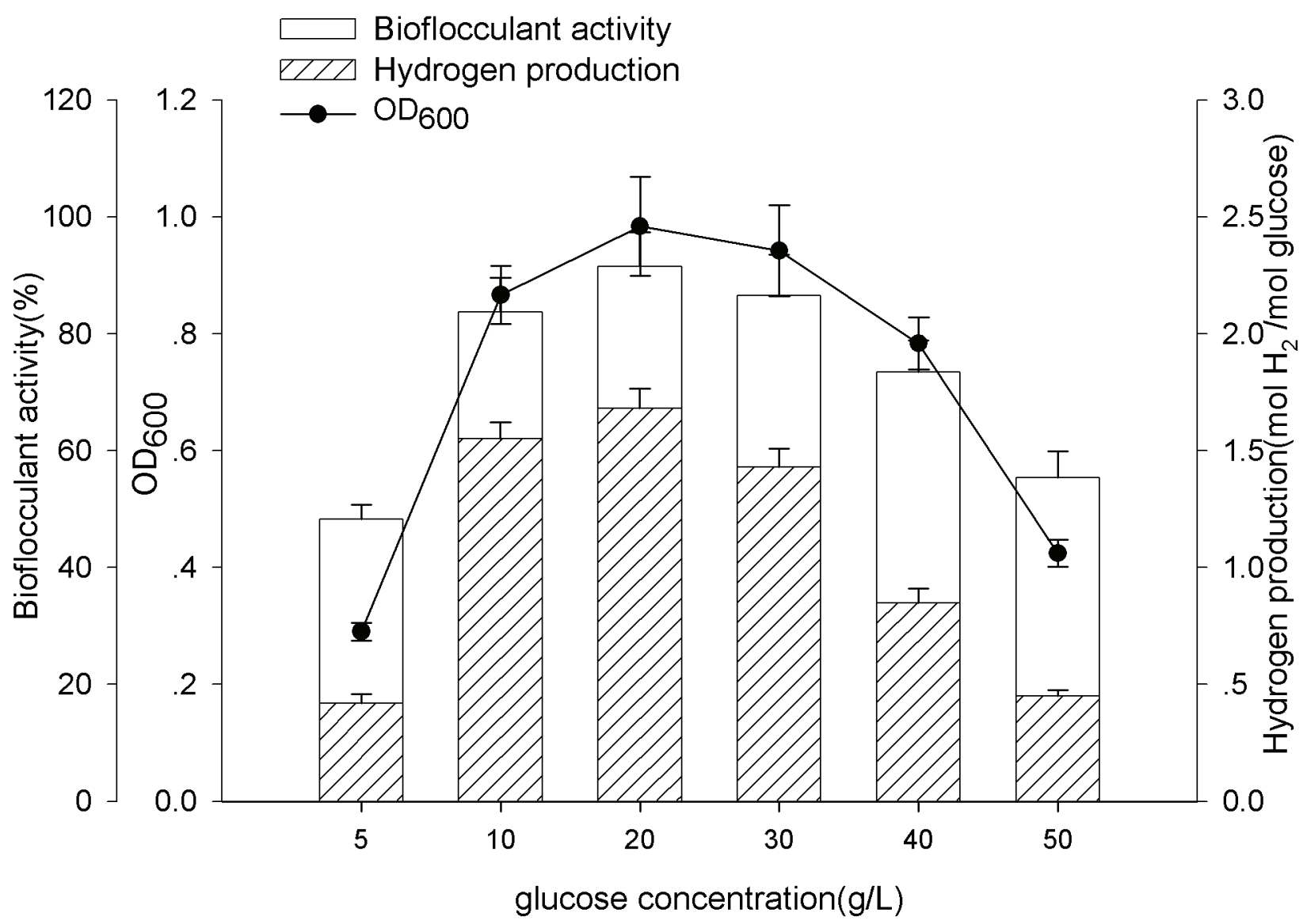




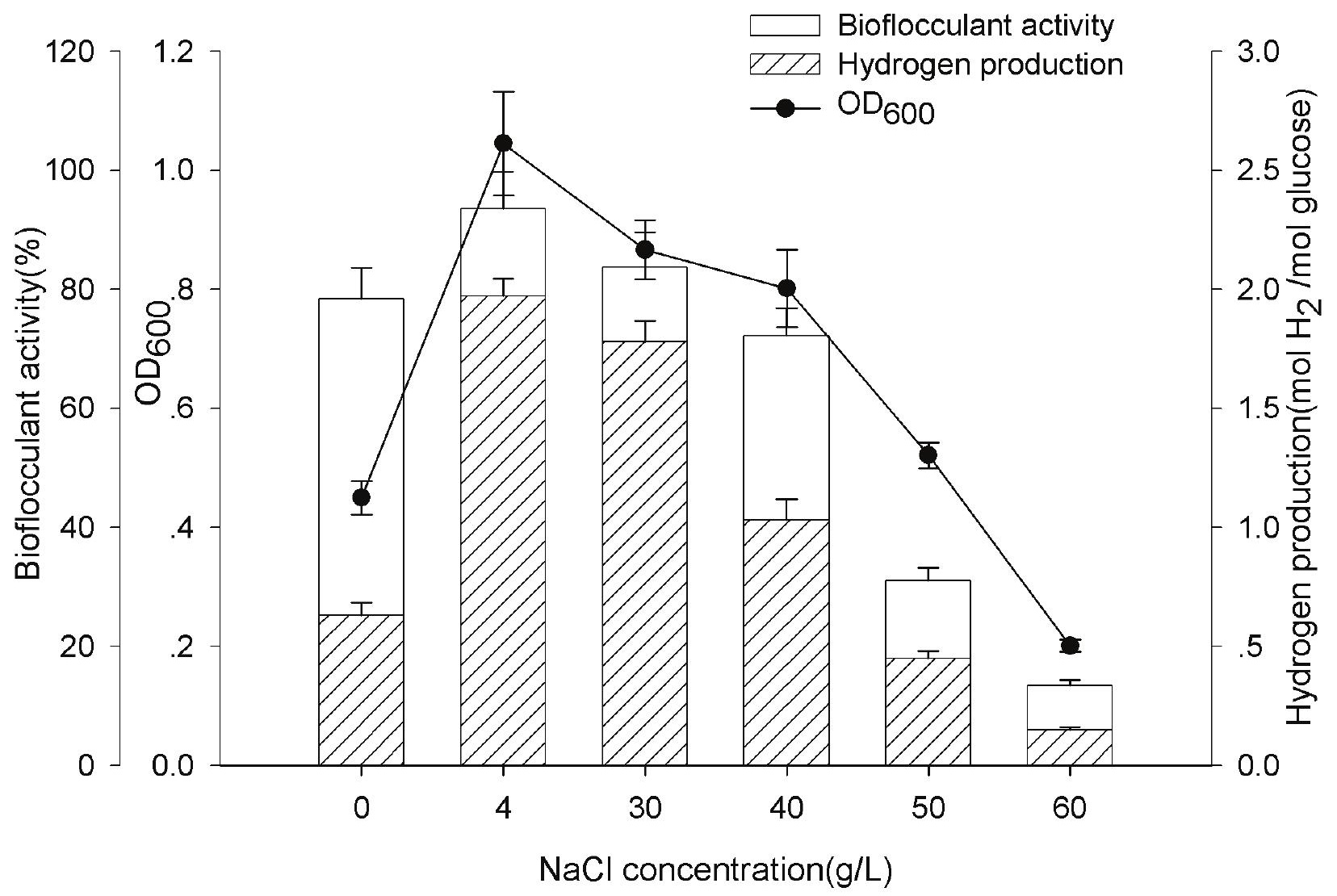

